\title{
Preparation for the scholar's role: first-year doctoral students in Tsinghua University
}

\author{
Fei Guo ${ }^{1,3} \cdot$ Ni Kang $^{2} \cdot$ Jinghuan Shi ${ }^{1,3}$
}

Published online: 24 May 2018

(c) Education Research Institute, Seoul National University, Seoul, Korea 2018

\begin{abstract}
Doctoral education programs, being the cradle of the next-generation scientists and scholars, undertake the mission of transforming a talented student into a promising scholar. This transformation is featured by two simultaneous processes: academic professionalization and scholarly socialization. Institutional environment, academic advisors, and more importantly the interaction between these factors and individual students play the key roles in the transformation. Using data from a longitudinal survey of Cohort 2014 doctoral students in Tsinghua University, this study explores students' experience during the first year in a doctoral program - a crucial stage of the transformation, with a focus on their preparation for and initial adaption to the role of a scholar. Implications for doctoral students, academic advisors, and institutions are discussed based on the findings.
\end{abstract}

Keywords Doctoral student development $\cdot$ Socialization of scholars $\cdot$ First-year experience $\cdot$ Tsinghua University

\section{Introduction}

As the globalization in the new century accelerates the world-wide competition of innovation and technology development, China places more and more emphasis on cultivating innovative talents with the launch of the "Double Excellence Project" (also called "Double World-Class Construction") which is considered as "the third national strategic effort in developing higher education following the '211' Project ${ }^{1}$ and '985' Project ${ }^{2} .{ }^{3}$ Top research universities in the knowledge-driven society stand at the frontline of the global competition with a core mission of talent cultivation Doctoral education is considered as one cornerstone of this core mission. Dr. Yong Qiu, the President of Tsinghua University, said in his recent paper that, "Excellent doctoral education reflects the 'height' of talent training of a worldclass university" (Qiu 2017). In 2016, 94\% of higher education institutions (HEIs) with doctoral programs voluntarily

Jinghuan Shi

shijhuan@tsinghua.edu.cn

Institute of Education, Tsinghua University, Beijing, China

2 Administrative Office of the Graduate School and Office of the Provost, Tsinghua University, Beijing, China

3 Center for the Assessment of College and Student Development, Tsinghua University, Beijing, China participated in the Fourth National Subject Evaluation organized by China Academic Degrees and Graduate Education Development Centre (CDGDC), showing the high profile of doctoral education in China.

Doctoral education in China expanded rapidly in the past two decades. According to the statistics from the Minister of Education (MOE) of China, the total enrolment of doctoral students in 1997 was 39,927 students. ${ }^{4}$ By 2015, the doctoral enrolment has increased more than sevenfold to 326,687 . Of this figure, 74,416 were new entrants to the doctoral programm and 53,778 were graduating doctoral students. ${ }^{5}$ Quantity expansion is always accompanied by the concern of quality, so as in doctoral education. Although both the government and the universities have

\footnotetext{
1 The "211" Project was initiated by the State Council of People's Republic of China in 1995 to construct research universities with excellent disciplinary programs nation-wide. 112 universities and colleges were funded by this project.

2 The "985" Project started in 1998 with a focus on the construction of the "world-class university." 39 universities from the "211" Project were selected to receive additional financial supports from the central or provincial governments.

3 The website of the Minister of Education, People's Republic of China. http://www.moe.edu.cn/jyb_xwfb/moe_2082/zl_2018n /2018_03/201801/t20180103_323595.html.

4 http://www.moe.gov.cn/s78/A03/moe_560/moe_569/moe_577/tnull 3099.html.

5 Data source: http://www.moe.edu.cn/s78/A03/moe_560/jytjs j_2015/2015_qg/201610/t20161012_284510.html.
} 
made efforts to increase and maintain the quality of postgraduate education, some basic issues remain unanswered, such as how to define the role of doctoral students, how to evaluate their learning quality, what are the key elements affecting their success, and how to build up a system to insure the effectiveness of doctoral education.

Since doctoral education in China is still an emerging part of higher education, both in practice and as a research domain, the policy and decision making in governmental and institutional level is closely connected with the reform efforts and research findings in the fields. Therefore, leading research universities in China, such as Tsinghua University, play an important role in piloting both in practice and in research.

This paper focuses on doctoral student's first-year learning experience in Tsinghua University. This is a special period when students first enter the professional community of scholars and researchers. They on one hand need to obtain knowledge and skills required by the profession, while on the other hand need to adjust themselves to get integrated into the community. The socialization of graduate/doctoral students has been discussed in the higher education literature in the West (see for example, Anderson and Anderson 2012; Austin 2002; Gardner and Mendoza 2010; Kim 2009; Sweitzer 2009; Weidman 2006; Weidman and Stein 2003). The recent article by Rhoads et al. (2017) is one of the few studies that focus on the socialization of graduate students in China. Comparing social science students in two universities in China and the U.S., the authors found that there is a culture difference between the two countries in doctoral preparation and socialization in China happens in a more informal way (Rhoads et al. 2017). The existing Chinese literature on doctoral education focuses more on students' career choice rather than the professionalization and socialization process (Bao et al. 2017; Jiang 2011; Lu 2011; Zhao and Hong 2014). Our study aims to examine the preparation and socialization of doctoral students in their first year.

Using data from a doctoral student survey, this study asks two research questions:

(1) What are the gains and adaptation outcomes of doctoral students in their first year in Tsinghua University?

(2) What factors influence doctoral students' gains and adaptation in the first year?

By answering these questions, this paper explores how to facilitate the preparation and socialization of doctoral students for the scholar's role in their first year. Studying this issue in Tsinghua University, one of the leading research universities in China and a pioneer in doctoral education, would provide meaningful insights for doctoral education quality improvement in China.

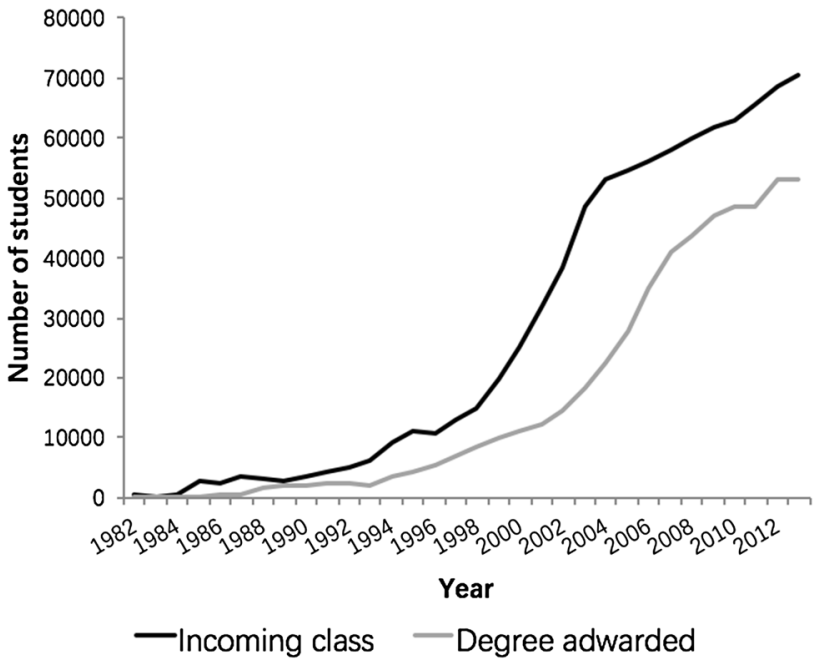

Fig. 1 Expansion of doctoral education in China. Reproduced with permission from Annual report on graduate education in China 2014

The rest of the paper first briefly discusses the development of Chinese doctoral education and reform in Tsinghua University as a background, and then proposes a theoretical framework to understand doctoral student's experience based on previous studies, presents the data, methods, and findings, and concludes with discussion and policy implications.

\section{Background: development of Chinese doctoral education and reform in Tsinghua University}

The Chinese doctoral education experienced four stages of development since 1981 when the national-level regulation, the Academic Degree Regulation of Peoples' Republic of China, was issued. As shown in Fig. 1, the first stage from 1981 to 1992 witnessed the establishment of the system. The annual enrolment of doctoral degree students increased gradually in the first period from 1981 to 1992 and surpassed 5000 in 1992. The second stage from 1992 to 1998 is a steady growth period, and the annual enrolment reached 14,962 in 1998 . Then the expansion stage came along with the expansion of the whole higher education system since 1999. The enrolment increased rapid by nearly $6400 \mathrm{stu}-$ dents per year and reached 53,284 in 2004. Since 2005, the speed of growing was decelerated. The policy emphasis was shifted gradually from quantitative expansion to quality assurance.

Along with the development and expansion of doctoral education, the responsibility of quality assurance gradually shifted from the central government to individual institutions. In the first period from 1980s to early 1990s, government-led assessment was the main body of quality 


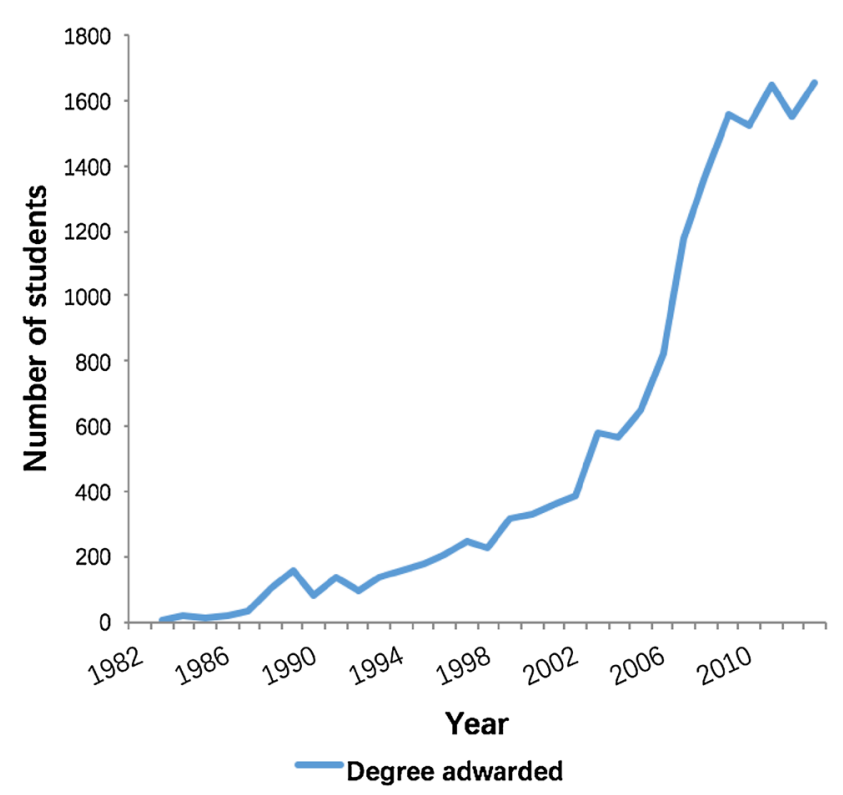

Fig. 2 Number of doctoral degree awarded in Tsinghua University, 1982-2015. Reproduced with permission from Annual book of Tsinghua University 2015

assurance. Then third-party assessment agencies started to emerge in mid-1990s. After 2000, individual universities were asked to take more responsibilities in guaranteeing doctoral education quality. In 2013, China carried out the Plan of Deepening the Reform of Postgraduate Education with a goal to improve education quality and to better serve the societal need of innovative talents. Student development was placed at the center and more emphasis was given to advisors' responsibility in cultivating innovative scholars and researchers. China started to construct an institutionalbased quality assurance system for doctoral education.

Following the national trend, Tsinghua University also experienced a rapid development of doctoral education as shown in Fig. 2. Tsinghua was previous a university focussed on engineering education. From 1994 to 2002, the university established eight new colleges and professional schools and completed the accreditation of doctoral programs with the MOE in China. It successfully transformed into a comprehensive research university. As one of the "985 Project" university in China, Tsinghua University, with increasing funding and support to scientific research and a high-quality faculty team, developed rapidly from 2003 to 2011 and gradually established a world-wide fame as a leading research university in China. This development was accompanied by a rapid increase of doctoral students' enrolment. By September 2015, the total enrolment of doctoral students reached 9917.

In 2012, the university established the goal to build a world-class research university. Doctoral students as the powerhouse of future scientific development received more and more attentions from the university leaders. With such a large scale of doctoral enrolment, the university was under the pressure of quality assurance and improvement. This pressure created a series of reforms for doctoral education. First, since 2016, Tsinghua exempts all doctoral program applicants from the national doctoral program examination. The acceptance decisions are to be made solely on application materials and performance at on-site interviews. Second, as the University completed the personnel system reform in recent years, all tenure-track faculty, including assistant professors, are approved to mentor doctoral students. Before the reform, only established professors were eligible, and they had to go through a rigorous review process to be approved as a doctoral advisor. These reforms raise more concerns about the quality of doctoral education.

Facing with these questions, the Graduate School and the Institute of Education of Tsinghua University jointly initiated a longitudinal survey of doctoral students in the year of 2014. The project was designed to track students through the doctoral program in order to better understand their experience and development as a young scholar. This paper uses the baseline and the first-round follow-up data of the survey to explore students' first-year experience in doctoral programs in Tsinghua University. The survey and sample are explained in detail in the "Method and data" section.

\section{Theoretical framework: doctoral training as a legitimate peripheral practice}

The theoretical framework of this study is drawn from the Weidman-Twale-Stein model of graduate student socialization (Weidman 2006) and the idea of legitimate peripheral participation (Lave and Wenger 1991). According to the Weidman-Twale-Stein socialization model, professional graduate school is a place where students trying to enter a profession acquire knowledge and skills required by the profession and reconstruct and adapt personal values to the common values and culture of the profession. This is an iterative process happening through interactions with people and the environment in graduate school as well as in the professional community. Similarly, Legitimate Peripheral Participation (LPP) is a process when newcomers of a professional community accumulate knowledge and experience through practice or collaborative project with the community's practitioners.

Considering academia as a professional community, doctoral programs that prepare future scholars can be considered as professional training programs. Yet, unlike typical professional graduate schools, such as business school and medical school, that provide trainings in a setting different from the real professional settings, doctoral programs are offered in a setting where most of the graduates are going to 


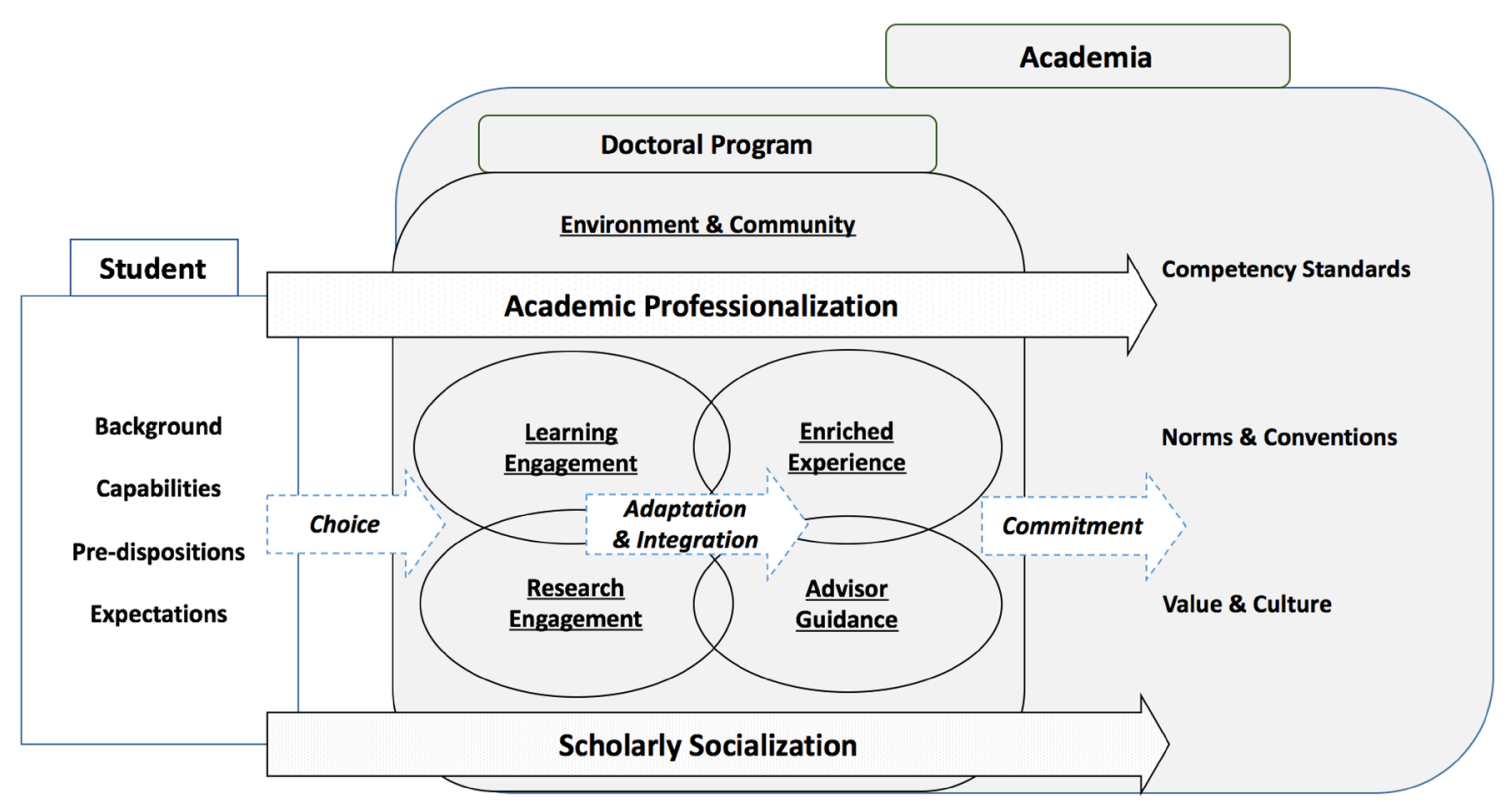

Fig. 3 Doctoral training as a legitimate peripheral practice

work in. Doctoral students are the newcomers to this community. They learn knowledge, skills, and values directly from experts in the profession (i.e., established scholars) and participate in real tasks of the profession (i.e., academic tasks). In this way, doctoral training could be considered as a Legitimate Peripheral Participation through which students learn to become a member of the community, or in another word, a scholar.

The framework in Fig. 3 describes how doctoral students get prepared for academia. The academia consists of scholars sharing similar competency and common culture. To enter it, one needs to meet the threshold of knowledge and competencies, learn about and adapt to the norms and conventions of practices, and internalize and commit to commonly shared values. This is a process of simultaneous academic professionalization and scholarly socialization. Academic professionalization involves knowledge learning and skills improving, while scholarly socialization involves the learning and internalization of the value and culture attached to the role of scholar. Doctoral programs provide resources and the critical environment for this process.

As shown by the dashed arrows in Fig. 3, new doctoral students enter the program with their own background, expectation, and values. By choosing and participating in formal and informal learning and research activities, they obtain knowledge and skills, and interact with people who are already in the community (i.e., professors, scholars, peers, and senior students). All this experience contributes to students' reflection and adjustment of their pre-values, visions, and self-cognition. Such reflection and adjustment in turn determine students' next step of choices and actions.
After several circles of this iterative process, students may gradually meet the competency requirements, internalize the values of the community, and make the commitment to be a member of the community.

The underlined phrases in Fig. 3 are the five major factors considered to be important for doctoral student training (Bao et al. 2017; Boden et al. 2011; Gardner 2008; JazvacMartek et al. 2011; Lindholm 2004; Lu 2011; McAlpine et al. 2012; Rhoades and Sporn 2002; Zhao and Hong 2014). The first factor is "Environment" of the program. It includes basic learning and research conditions, course and academic requirements, academic climate in the program, and interdisciplinary and global collaborative environment of the program. These are the resources and environmental supports for doctoral training.

Learning and research are the main activities for doctoral students through which they learn and develop knowledge, skills, and dispositions (Bao et al. 2017; Jazvac-Martek et al. 2011; McAlpine et al. 2010). The factor "Learning Engagement" refers to students' active engagement in learning activities, including deep-learning in course work, active thinking on academic issues, active academic writing practice, and collaborative learning with other students and scholars. Students learn knowledge and methods through these activities. "Research Engagement" refers to students' involvement in research activities, including research projects led by professors and projects initiated by students. Students obtain research experience and improve research skills through these practices. "Enriched Experience" refers to informal academic activities, such as attending lectures, studying abroad, participating in academic conferences, 
Table 1 Sample description

\begin{tabular}{lllll}
\hline & $\begin{array}{l}\text { Cohort 2014 } \\
\text { (population) }\end{array}$ & $\begin{array}{l}\text { Beginners' } \\
\text { survey sample }\end{array}$ & $\begin{array}{l}\text { First-year sur- } \\
\text { vey sample }\end{array}$ & Tracked sample \\
\hline No. of observation & 1952 & 739 & 397 & 221 \\
Response/tracking rate & - & $37.86 \%$ & $20.34 \%$ & $11.32 \%$ \\
$\%$ of female students & $31.86 \%$ & $34.51 \%$ & $29.47 \%$ & $33.94 \%$ \\
$\%$ of BA-to-PhD students & $57.89 \%$ & $60.49 \%$ & $63.48 \%$ & $70.14 \%$ \\
Major distribution & & & & \\
$\quad$ Humanities and Social sciences & $19.16 \%$ & $11.64 \%$ & $7.56 \%$ & $6.33 \%$ \\
$\quad$ Sciences & $24.64 \%$ & $25.98 \%$ & $19.65 \%$ & $16.74 \%$ \\
Engineering & $56.20 \%$ & $54.13 \%$ & $66.50 \%$ & $69.68 \%$ \\
Analytic sample size & & 676 & 364 & 203 \\
\hline
\end{tabular}

submitting papers to academic journals, and so forth. Students broaden their horizon and build connections with the academia outside the doctoral program through these activities.

Last but maybe the most important, advisor's guidance is a crucial factor for the success of doctoral training (Anderson and Anderson 2012; Barnes and Austin 2009; Curtin et al. 2013; Eby et al. 2008; Hall and Burns 2009). In most cases, advisors are the ones who work most closely with doctoral students during the program. They are the mentor and model from whom novice scholars learn knowledge, skills, and most importantly the values and ethics of the scholars' community. Therefore, in the factor of "Advisor Guidance," we not only include advices on academic work, but also include scholarly guidance such as introducing the student to the academia community and establishing equal scholarly relationship between the advisor and student.

Overall, the conceptual framework presented above provides a comprehensive way to understand and evaluate doctoral training program. For this specific paper, we focus on doctoral students experience in the first year. The first year is the very beginning of the simultaneous academic professionalization and scholarly socialization process. There might be conflicts and problems that may hinder the progress of doctoral training. The aim of this paper is to identify the problems and explore possible ways to help students get through the process.

\section{Method and data}

We employ quantitative research methods to answer the two research questions, taking advantage of an institutional-wide longitudinal survey of doctoral students. Specifically, the first question is answered with descriptive depiction of students' motivation, experience, and adaptation progress in the first year. Regression analysis is then used to explore factors influencing students' adaptation. The following of this section discusses the data and model in detail.

\section{Data and sample}

With the aim to improving doctoral education in Tsinghua, the Graduate School and the Institute of Education of Tsinghua University initiated the Longitudinal Survey of Doctoral Students in Tsinghua University (LSDS-THU) in the year of 2014. The project traces doctoral students throughout their years in Tsinghua via four rounds of online questionnaire survey at four crucial time points: at the beginning of the doctoral program (the Beginners' Survey), after the first year (the First-year Survey), upon certified (the Experience Survey), and upon graduation (the Graduation Survey). The project is designed based on the framework as presented in Fig. 3. Specifically, the Beginners' survey asks about students' motivations and expectation of pursuing a doctoral degree, career expectation after completing the degree, and self-assessment on ability and skills. The First-year Survey asks about students' experience, attitudes, and gains and accomplishments in the first year. The Experience Survey also asks about experience, but focuses more on research engagement and program progress. Finally, the Graduation Survey asks about achievement and gains in the doctoral program, satisfaction, and placement after graduation. The questionnaires are developed based on relevant theories and existing scales and questionnaires. ${ }^{6}$ In each round of survey, invitations are sent out to all doctoral students through the student information systems to target a total population sample, but the response rate varies by cohort and tends to decrease by year.

In this particular paper, we use the sample of Cohort 2014 students who entered doctoral programs in Tsinghua University in September 2014. As shown in Table 1, the total

\footnotetext{
${ }^{6}$ The existing scales/questionnaires (e.g., on motivation, self-efficacy, engagement, career plan, etc.) are mostly in English language. We translated them into Chinese with some cultural adaptation, and also created items to reflect the context of Chinese doctoral education. The instruments were pilot-tested in June 2014 before its formal launch in that September.
} 
population of the cohort is 1952 , of which 1839 are from Mainland China. The response rate of the Beginners' survey conducted in September 2014 is 37.9\% (739 students), and that of the First-year Survey conducted in January 2016 is $20.3 \%$ (397 students). 221 students answered both the Baseline and the First-year surveys, accounting for $11.3 \%$ of the whole population and $30 \%$ of those who completed the Beginners' survey. The high non-response rate and attrition rate introduce some bias to our sample in terms of student background. As shown in Table 1, comparing to the whole Cohort 2014, the responded samples (especially the tracked sample) are over-represented by students who entered doctoral programs directly after undergraduate studies (hereafter referred to as the BA-to-PhD students) and students with engineering majors, and under-represented of students who obtained a Bachelor's degree from Tsinghua University (hereafter referred to as the Tsinghua Bachelor holders). ${ }^{7}$ To adjust for the imbalance in sample structure, we construct weights based on gender, major, and whether being a BAto-PhD student for each sample and apply the weights in the analysis below. In addition, about $7 \%$ of students in the responded samples are in special programs and therefore excluded from the analysis. The final analytic sample size for each sample is presented in the bottom of Table 1 .

\section{Models}

As described in the conceptual framework, doctoral program is a legitimate peripheral practice through which students gradually develop into scholars. It is a simultaneous process of academic professionalization and scholarly socialization. Therefore, in examining students' adaptation to the scholar's role, we need to consider both academic gains as well as socialization outcomes.

Specifically, we identify two sets of developmental outcomes to indicate adaptation. The first set is academic outcomes, including self-reported gains in content knowledge, academic skills, and academic dispositions over the first year. These variables are constructed from 6-point Likert items in the First-year survey. ${ }^{8}$ The definition and measurement are presented in Table 8 in the "Appendix."

The second set is socialization outcomes. We use selfassessment on the level of knowledge and level of research

\footnotetext{
7 The BA-to-PhD students are those who got admitted to doctoral programs without a masters' degree, but they may have done their undergraduate studies in other universities. The Tsinghua Bachelor holders are those who did the undergraduate in Tsinghua University, but may have already studied in a master program prior to the doctoral program.

${ }^{8}$ For easier interpretation, we divide the scale into several intervals: [4.5, 6]: "positive/large," [3, 4.5]: "neutral/medium," and [1, 3]: "negative/small."
}

method skills to indicate self-efficacy, use certainty about ones' research concentration to indicate commitment, use attitudes and beliefs about the meaning of research work to measure research aspiration, use self-reported familiarity with the academia to indicate social integration, and use overall satisfaction with the current research area to indicate academic integration. The definition and measurement of these variables are also presented in Table 8 in the "Appendix." The items appear in both the Beginners' Survey and the First-year Survey, allowing us to examine the change in these aspects after the first year. We expect increased level of knowledge and skills, increased research aspiration, and increased level of integration as students getting better prepared for the scholar's role.

Furthermore, we use regression analysis to explore influential factors of students' adaptation under the guidance of the analytical framework. The general model is presented below:

$\mathrm{ADP}_{i}=\beta_{0}+\beta_{1} P_{i}+\beta_{2} M_{i}+\beta_{3} \mathrm{EV}_{i}+\beta_{4} \mathrm{SAI}_{i}+\beta_{5} \mathrm{LRE}_{i}+\varepsilon_{i}$.

As shown in Model 1, the adaptation outcomes are used as the dependent variables $\left(\mathrm{ADP}_{i}\right)$. The explanatory variables include student personal characteristics $\left(P_{\mathrm{i}}\right)$, motivation $\left(M_{i}\right)$, environment $\left(\mathrm{EV}_{i}\right)$, student-advisor interaction $\left(\mathrm{SAI}_{i}\right)$, and learning and research experience $\left(\mathrm{LRE}_{i}\right)$. Table 8 in the "Appendix" presents definition and measures of the explanatory and outcome variables.

\section{Results and findings}

This section first presents descriptive findings on the motivation and expectation of beginning doctoral students and their experience and adaptation outcomes in the first year, and then presents the regression analysis to explore how motivation and first-year experience influence adaptation.

\section{Motivation and expectation of beginning doctoral students in Tsinghua University}

Table 2 presents the mean scores on indicators of students' motivation and expectation. Motivation is measured with two indicators: Intrinsic motives and Extrinsic Incentives. As it shows, the average score of the baseline sample on Intrinsic Motives is higher than that on Extrinsic Incentives. Specifically, $73.5 \%$ of the baseline sample consider "self-challenge and improvement" as an important motive to pursue a doctoral degree (highest among the items for Intrinsic Motives). Yet, $30.7 \%$ of the sample also admit that it is just an inertia to get to the next level of education after completing a degree (highest among the items for Extrinsic Incentives). 
Table 2 Motivation and expectation of beginning doctoral students in Tsinghua (from the Beginners' survey)
Table 3 First-year experience in Tsinghua doctoral programs (from first-year survey)

\begin{tabular}{|c|c|c|c|c|c|c|}
\hline \multirow[t]{2}{*}{ Variables } & \multicolumn{3}{|c|}{ Baseline sample } & \multicolumn{3}{|c|}{ Tracked sample } \\
\hline & $N$ & Mean & SD & $N$ & Mean & $\mathrm{SD}$ \\
\hline Intrinsic motives & 674 & 4.86 & 0.78 & 201 & 4.87 & 0.78 \\
\hline Extrinsic incentives & 674 & 3.50 & 0.97 & 201 & 3.58 & 1.00 \\
\hline \multicolumn{7}{|l|}{ Career expectation } \\
\hline Career-academic & 675 & 4.14 & 0.98 & 202 & 4.26 & 0.85 \\
\hline Career-administrative & 675 & 3.36 & 1.13 & 202 & 3.35 & 1.11 \\
\hline Career-industry & 675 & 3.76 & 1.13 & 202 & 3.78 & 1.17 \\
\hline
\end{tabular}

Variables are on a 1-6 scale. Analytic weights applied

\begin{tabular}{|c|c|c|c|c|c|c|}
\hline \multirow[t]{2}{*}{ Variables } & \multicolumn{3}{|c|}{ First-year sample } & \multicolumn{3}{|c|}{ Tracked sample } \\
\hline & $\mathrm{N}$ & Mean & SD & $\mathrm{N}$ & Mean & $\mathrm{SD}$ \\
\hline \multicolumn{7}{|l|}{ Environment } \\
\hline Program environment* & 362 & -0.03 & 0.88 & 201 & -0.04 & 0.82 \\
\hline Facilities & 362 & 4.87 & 0.81 & 201 & 4.90 & 0.75 \\
\hline Academic climate & 362 & 4.73 & 0.91 & 201 & 4.70 & 0.90 \\
\hline Interdisciplinary collaboration & 362 & 4.20 & 1.04 & 201 & 4.18 & 1.02 \\
\hline Program requirement & 362 & 4.85 & 0.81 & 201 & 4.83 & 0.79 \\
\hline Innovative climate in research team & 268 & 4.93 & 0.98 & 154 & 5.02 & 0.84 \\
\hline Globalization environment & 362 & 4.51 & 1.00 & 201 & 4.52 & 0.95 \\
\hline \multicolumn{7}{|l|}{ Student-advisor interaction } \\
\hline Academic advice* & 362 & -0.08 & 1.04 & 201 & -0.05 & 1.06 \\
\hline Availability & 362 & 4.93 & 1.11 & 201 & 4.96 & 1.11 \\
\hline Capability & 362 & 4.99 & 1.10 & 201 & 5.02 & 1.09 \\
\hline Encouragement & 362 & 5.08 & 1.00 & 201 & 5.12 & 1.03 \\
\hline Scholarship guidance* & 362 & -0.06 & 1.05 & 201 & -0.04 & 1.04 \\
\hline Equal relationship & 362 & 4.97 & 1.03 & 201 & 5.00 & 1.06 \\
\hline Guidance to academia & 362 & 4.81 & 1.19 & 201 & 4.81 & 1.13 \\
\hline \multicolumn{7}{|l|}{ Learning and research experience } \\
\hline Active and collaborative learning & 362 & 4.37 & 0.69 & 201 & 4.34 & 0.69 \\
\hline Research engagement & 267 & 4.65 & 0.82 & 153 & 4.72 & 0.78 \\
\hline
\end{tabular}

*Standardized construct. Variables without * are on a 1-6 scale. Analytic weights applied
As for career expectation, most beginning doctoral students expect to work in the academia. Specifically, university faculty is the most popular job. $67.4 \%$ of the baseline sample report willing or very willing to take this kind of job, followed by research job in research institutes $(58.9 \%)$ and post-doctoral positions abroad (55.1\%). But only $16.7 \%$ of the sample are willing to do post-doctoral research in China. Industry and government is also attractive to beginning doctoral students. $45.8 \%$ of the sample are willing or very willing to work in a business enterprise, $35.1 \%$ in the governments, and $28.2 \%$ to start ones' own business. Administrative work is the least popular type. Less than $25 \%$ of the sample are willing to take this type of job. There is also a gender difference in career expectation: female students are more willing to work in higher education institutions, and male students are more willing to work in the industry.
It is worth pointing out that, as the Table shows, the tracked sample and the baseline sample do not differ much in intrinsic motives, extrinsic incentives, and career expectation (the $p$ values of the $T$ test are all above .1). This indicates that the selection bias of the tracked sample with regard to motivation and background is negligible.

\section{First-year experience in Tsinghua University}

Table 3 presents the mean scores on the first-year experience indicators. Overall, students in the first-year survey sample are satisfied with the program environment and research climate, and participate actively in research activities. Relatively, the indicators on "Interdisciplinary collaboration" and "Active and collaborative learning" receive lower scores. Looking into the items, only $34 \%$ of the sample 


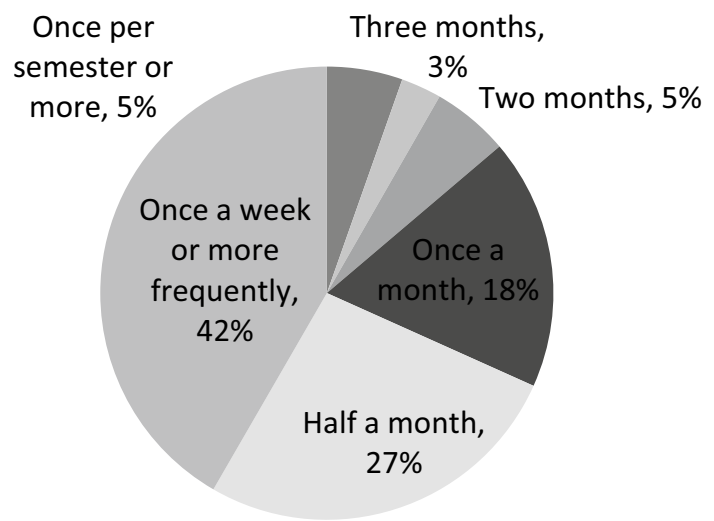

Fig. 4 Frequency of communication between doctoral students and advisors

report having opportunities to join interdisciplinary research teams, and only $36 \%$ of the sample frequently conduct academic writing.

With regard to student-advisor interaction, most students have frequent interaction with their advisors. As shown in Fig. 4 , about $70 \%$ of the sample meet up with their advisor at least once every 2 weeks. Yet about $13 \%$ of students in the sample meet advisors less than once per month. As for advisors' guidance and help, most students give a positive evaluation, especially on academic encouragement and feedback. But the score on guidance into professional community is relatively lower, especially for the item "Advisor provides suggestions on my career development" $(4.66 \pm 1.32)$. As shown in the survey, the most common topic between students and advisors (91\%) is research related issues. Only $18 \%$ of the sample report talking about career development and personal life with their advisors. The survey also reveals that many doctoral students only work with their advisors: only $15.7 \%$ of the sample frequently discuss questions with other faculty members, and about $24.4 \%$ rarely or never discuss with other faculty members.

As shown in Table 3, the differences in mean scores between the tracked sample and the first-year sample are very small ( $p$ values all above .1), indicating that the selection bias of the tracked sample with regarding to experience indicators is negligible.

\section{Doctoral students' adaptation to the scholars' role}

\section{Academic preparation}

Table 4 presents students' self-reported academic gains in the first year. As the Table shows, students gain most in academic dispositions in the first year: about $60 \%$ of the sample report much or very much improvement in academic ethics and norms, and about $46 \%$ report improvement in academic aspiration. For academic skills and abilities, $40-45 \%$ of the sample report much or very much improvement in research, writing, communication, and collaboration skills, but only about 35\% report improvement in academic innovative ability. For knowledge, less than half $(45-47 \%)$ of the students report large gains in fundamental and advanced knowledge of their major field, and about $25 \%$ report gains in knowledge in other fields. Comparing the first-year sample
Table 4 Self-reported academic gains in first year (from firstyear survey)

\begin{tabular}{|c|c|c|c|c|c|c|}
\hline \multirow{2}{*}{$\begin{array}{l}\text { Q: To what extent you made improve- } \\
\text { ment in the following aspects? }\end{array}$} & \multicolumn{3}{|c|}{ First-year sample (364 obs.) } & \multicolumn{3}{|c|}{ Tracked sample (203 obs.) } \\
\hline & $\begin{array}{l}\% \text { of "much" to } \\
\text { "very much" }\end{array}$ & Mean & SD & $\begin{array}{l}\% \text { of "much" to } \\
\text { "very much" }\end{array}$ & Mean & SD \\
\hline Knowledge & & 4.10 & 0.98 & & 4.11 & 0.99 \\
\hline Advanced knowledge in major field & 46.7 & 4.36 & 1.12 & 45.9 & 4.43 & 1.08 \\
\hline Fundamental knowledge in major field & 46.9 & 4.28 & 1.13 & 45.4 & 4.30 & 1.13 \\
\hline Knowledge in other fields & 24.4 & 3.66 & 1.18 & 27.7 & 3.62 & 1.30 \\
\hline Academic skills & & 4.16 & 1.00 & & 4.13 & 1.06 \\
\hline Skill of conducting research & 45.3 & 4.23 & 1.17 & 43.5 & 4.19 & 1.22 \\
\hline Academic writing & 40.3 & 4.08 & 1.17 & 38.2 & 4.01 & 1.25 \\
\hline Academic communication & 42.7 & 4.21 & 1.10 & 39.1 & 4.22 & 1.07 \\
\hline Academic innovation & 35.7 & 4.03 & 1.11 & 35.1 & 4.01 & 1.17 \\
\hline Effective collaboration with others & 45.3 & 4.25 & 1.12 & 43.0 & 4.19 & 1.18 \\
\hline Academic dispositions & & 4.40 & 0.90 & & 4.39 & 0.87 \\
\hline Academic aspiration & 46.6 & 4.26 & 1.13 & 46.1 & 4.30 & 1.09 \\
\hline Academic norms & 58.0 & 4.60 & 1.02 & 56.6 & 4.60 & 0.99 \\
\hline Academic ethics & 61.4 & 4.68 & 0.99 & 58.2 & 4.61 & 0.95 \\
\hline Future development plan & 39.8 & 4.08 & 1.21 & 38.9 & 4.08 & 1.13 \\
\hline
\end{tabular}

Analytic weights applied 
Table 5 Self-assessment, attitude, and integration of firstyear doctoral students (tracked sample, 203 obs.)

\begin{tabular}{|c|c|c|c|c|}
\hline & \multicolumn{2}{|c|}{$\begin{array}{l}\% \text { of "much" to "very } \\
\text { much" }\end{array}$} & \multicolumn{2}{|c|}{ Individual change } \\
\hline & $\begin{array}{l}\text { Beginners' } \\
\text { survey (\%) }\end{array}$ & $\begin{array}{l}\text { First-year } \\
\text { survey }(\%)\end{array}$ & $\begin{array}{l}\% \text { of } \\
\text { improved } \\
(\%)\end{array}$ & $\begin{array}{l}\% \text { of } \\
\text { declined } \\
(\%)\end{array}$ \\
\hline \multicolumn{5}{|l|}{ Self-assessment } \\
\hline Level of content knowledge & 37.7 & 55.5 & 48.8 & 14.9 \\
\hline Level of research methodology & 21.2 & 46.1 & 48.3 & 12.3 \\
\hline Certainty of research concentration & 45.3 & 52.8 & 36.9 & 18.4 \\
\hline \multicolumn{5}{|l|}{ Attitude and aspiration } \\
\hline Believe that own research has great contribution & 73.7 & 72.9 & 23.1 & 18.7 \\
\hline Believe that research could contribute to practice & 72.7 & 77.1 & 24.5 & 24.8 \\
\hline Sense of self-achievement from research & 70.6 & 71.1 & 18.4 & 20.4 \\
\hline \multicolumn{5}{|l|}{ Integration } \\
\hline Academic: satisfaction on current research area & 53.3 & 49.5 & 32.1 & 26.5 \\
\hline Social: familiarity with the academia & 22.3 & 39.7 & 50.0 & 13.7 \\
\hline
\end{tabular}

Analytic weights applied with the tracked sample, there are slight differences in the percentage pointes, but the $T$ tests suggest that the mean scores are not significantly different from each other.

\section{Changes in attitudes}

Table 5 presents the mean scores on self-assessment, certainty about research concentration, research attitudes and aspiration, and academic and social integration of the tracked sample in the Beginners' survey and the First-year survey. As shown in the left panel of the Table, at the beginning of the doctoral program, most students are modest about their level of knowledge and method. No more than one-third of the tracked sample give positive self-assessment on these aspects. Yet, after the first year, about half of students think positively about their knowledge and skills. The percentage of students with clear research concentration goals also increase by $9 \%$ points after 1 year. Research attitude and aspiration remain at a high level over the first year. As for integration, more students are getting familiar with the academia (increased by $17.4 \%$ points), but the percentage of students who feel satisfied with current research area decrease by about $5 \%$ points.

When comparing the answers of individual students on the same question in the two surveys, as shown in the right panel of Table 5, about $50 \%$ of students show improved self-assessment in knowledge and method and improved familiarity with the academia. However, about one-quarter of students show declined research aspiration and satisfaction on their research area, suggesting a decline in academic integration with the academia. About 20\% become less clear about their research concentration and lost confidence in making contribution through research.
There are also about $15 \%$ of students showing declined self-assessment and level of integration. These suggest that, while the majority of first-year doctoral students are making progress to get integrated into the academia, there is a significant group of students struggling with their firstyear doctoral life.

\section{Influential factors of doctoral students' first-year adaptation}

To explore the associations between first-year experience and adaptation outcomes, we estimate Model 1 with two types of regression. First, as the academic preparation outcomes (i.e., self-reported gains) are continuous variables, we use Ordinal Least Square (OLS) regression to estimate the models on these variables. Second, for socialization outcomes, we use Multinomial Logit regression to estimate the tendency of change during the first year (i.e., "improved" or "declined", using "unchanged" as the base category). As there are only 14 humanity and social science students in the tracked sample, we exclude them from the regression analysis. Therefore, the results only apply to science and engineering students. In addition, it needs to point out that the regression coefficients do not imply causal relationships but only indicate associations between the explanatory variables and the outcomes. The results are presented in Tables 6 and 7, respectively.

\section{Influential factors on academic preparation}

The OLS regression estimates of models with academic preparation outcomes are presented in Table 6. As it shows, 
Table 6 Regression: selfreported gains

\begin{tabular}{|c|c|c|c|}
\hline & $\begin{array}{l}(1) \\
\text { Knowledge } \\
\text { b/se }\end{array}$ & $\begin{array}{l}(2) \\
\text { Skills } \\
\text { b/se }\end{array}$ & $\begin{array}{l}\text { (3) } \\
\text { Dispositions } \\
\text { b/se }\end{array}$ \\
\hline \multicolumn{4}{|l|}{ Motivation } \\
\hline Intrinsic motives & $\begin{array}{l}0.149 * \\
(0.073)\end{array}$ & $\begin{array}{l}0.087 \\
(0.073)\end{array}$ & $\begin{array}{l}0.068 \\
(0.070)\end{array}$ \\
\hline Extrinsic incentive & $\begin{array}{l}0.083 \\
(0.060)\end{array}$ & $\begin{array}{l}0.102 \\
(0.061)\end{array}$ & $\begin{array}{l}0.041 \\
(0.058)\end{array}$ \\
\hline \multicolumn{4}{|l|}{ Career expectation } \\
\hline Career-academic & $\begin{array}{l}0.031 \\
(0.063)\end{array}$ & $\begin{array}{l}-0.123 \\
(0.064)\end{array}$ & $\begin{array}{c}-0.062 \\
(0.061)\end{array}$ \\
\hline Career-administrative & $\begin{array}{l}0.113 * \\
(0.052)\end{array}$ & $\begin{array}{l}0.119 * \\
(0.052)\end{array}$ & $\begin{array}{l}0.070 \\
(0.050)\end{array}$ \\
\hline Career-industry & $\begin{array}{l}-0.051 \\
(0.049)\end{array}$ & $\begin{array}{l}-0.015 \\
(0.050)\end{array}$ & $\begin{array}{l}-0.003 \\
(0.047)\end{array}$ \\
\hline \multicolumn{4}{|l|}{ Environment } \\
\hline Program environment & $\begin{array}{l}0.353 * * \\
(0.109)\end{array}$ & $\begin{array}{l}0.327 * * \\
(0.110)\end{array}$ & $\begin{array}{l}0.142 \\
(0.105)\end{array}$ \\
\hline Innovative climate in research team & $\begin{array}{l}0.092 \\
(0.111)\end{array}$ & $\begin{array}{l}0.067 \\
(0.112)\end{array}$ & $\begin{array}{l}0.237 * \\
(0.107)\end{array}$ \\
\hline Globalization environment & $\begin{array}{l}-0.009 \\
(0.082)\end{array}$ & $\begin{array}{l}-0.003 \\
(0.083)\end{array}$ & $\begin{array}{l}0.068 \\
(0.079)\end{array}$ \\
\hline \multicolumn{4}{|l|}{ Student-advisor interaction } \\
\hline Academic advice & $\begin{array}{l}-0.143 \\
(0.131)\end{array}$ & $\begin{array}{l}0.055 \\
(0.132)\end{array}$ & $\begin{array}{l}-0.070 \\
(0.126)\end{array}$ \\
\hline Scholarship guidance & $\begin{array}{l}0.027 \\
(0.124)\end{array}$ & $\begin{array}{l}-0.190 \\
(0.126)\end{array}$ & $\begin{array}{l}-0.021 \\
(0.120)\end{array}$ \\
\hline \multicolumn{4}{|l|}{ Learning and research experience } \\
\hline Active and collaborative learning & $\begin{array}{l}0.178 \\
(0.121)\end{array}$ & $\begin{array}{l}0.497 * * * \\
(0.122)\end{array}$ & $\begin{array}{l}0.302 * \\
(0.117)\end{array}$ \\
\hline Research engagement & $\begin{array}{l}0.380 * * * \\
(0.097)\end{array}$ & $\begin{array}{l}0.352 * * * \\
(0.098)\end{array}$ & $\begin{array}{l}0.161 \\
(0.093)\end{array}$ \\
\hline \multicolumn{4}{|l|}{ Demographic characteristics } \\
\hline Female & $\begin{array}{l}-0.254^{*} \\
(0.123)\end{array}$ & $\begin{array}{l}-0.059 \\
(0.124)\end{array}$ & $\begin{array}{l}-0.248^{*} \\
(0.119)\end{array}$ \\
\hline \multicolumn{4}{|c|}{ Undergraduate university type (Tsinghua as the ref. group) } \\
\hline Other "985" universities & $\begin{array}{l}-0.044 \\
(0.127)\end{array}$ & $\begin{array}{l}-0.064 \\
(0.128)\end{array}$ & $\begin{array}{l}-0.060 \\
(0.122)\end{array}$ \\
\hline "211" universities & $\begin{array}{l}-0.351 * \\
(0.152)\end{array}$ & $\begin{array}{l}-0.377^{*} \\
(0.153)\end{array}$ & $\begin{array}{l}-0.231 \\
(0.146)\end{array}$ \\
\hline Non-key universities & $\begin{array}{l}-0.772 * * * \\
(0.197)\end{array}$ & $\begin{array}{l}-0.524 * * \\
(0.199)\end{array}$ & $\begin{array}{l}-0.304 \\
(0.190)\end{array}$ \\
\hline Constant & $\begin{array}{l}0.074 \\
(0.814)\end{array}$ & $\begin{array}{l}-0.334 \\
(0.821)\end{array}$ & $\begin{array}{l}0.666 \\
(0.784)\end{array}$ \\
\hline Observations & 187 & 187 & 187 \\
\hline$R^{2}$ & 0.554 & 0.583 & 0.480 \\
\hline Adjusted $R^{2}$ & 0.512 & 0.543 & 0.431 \\
\hline
\end{tabular}

Robust standard errors in parentheses

$* * * p<.01, * * p<.05, * p<.1$ 


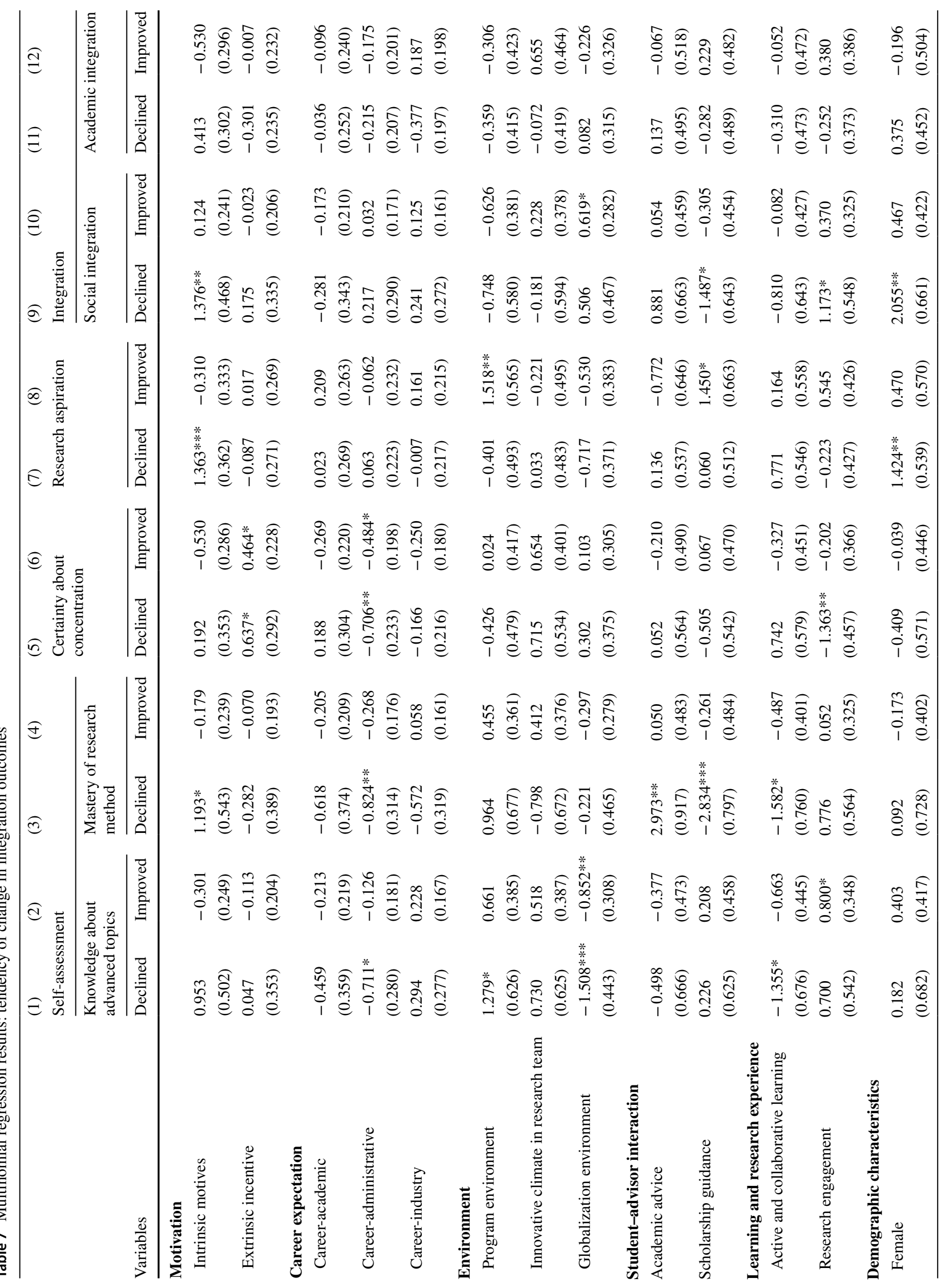




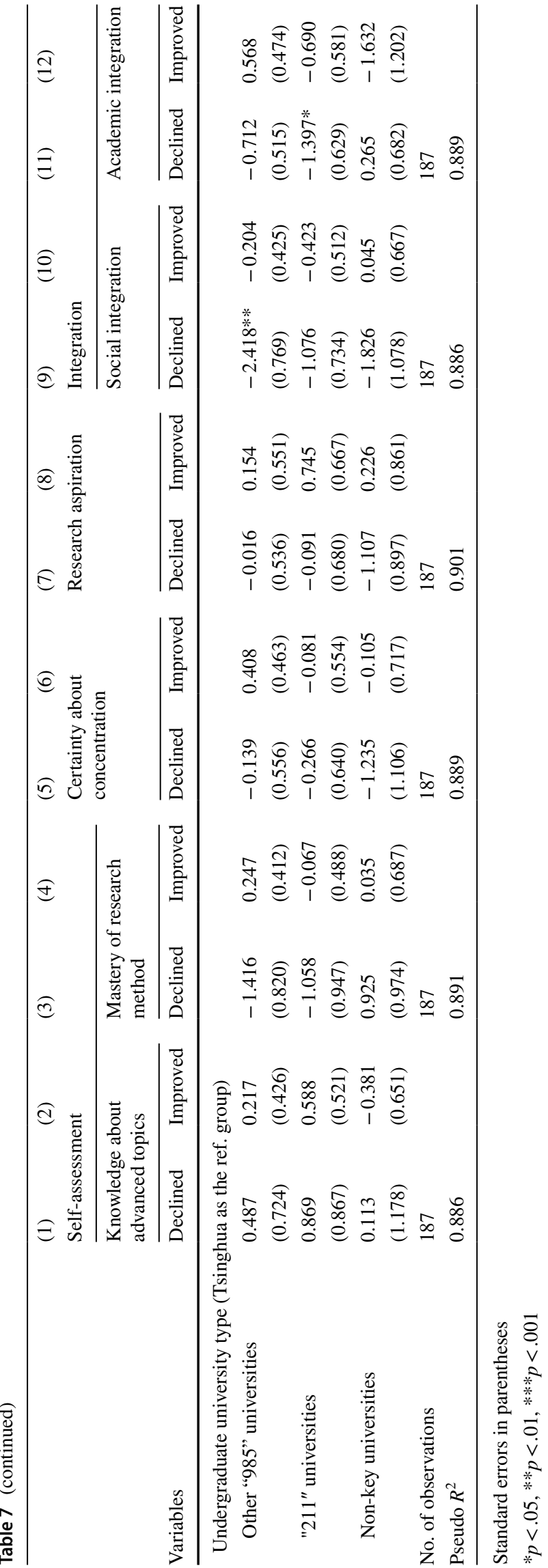

female students in general report less gains than male students. Students from " 211 " and non-key institutions report less gains compared to those from Tsinghua and other " 985 " universities. ${ }^{9}$ Gains in different aspects seem to be influenced by different factors. Holding other things constant, Knowledge gains is statistically significantly correlated with higher intrinsic motives, stronger willingness to do administrative work in the future, better program environment, and more engagement in research activities. Skill gains is statistically significantly associated with the willingness to do administrative work, better environment, more active and collaborative learning, and more research engagement. Gains in academic dispositions is only significantly associated with more active and collaborative learning and better research climate in one's research team. Overall, supportive program environment and engagement in learning and research activities appear to be the influential factors on student academic preparation in the first year, but there is no significant influence from advisers.

\section{Influential factors on first-year socialization}

Table 7 presents the multinomial logit regression outputs on first-year socialization outcomes as measured by the tendency of change in self-assessment, certainty about research concentration, research aspiration and attitudes, and integration outcomes. Compared to the males, female students show a trend of decline in research aspiration and social integration with the academia (i.e., familiarity with academia). Students holding bachelor degrees from Tsinghua University also tend to decline in both social and academic integration, compared to students from other elite universities. The influence of student motivation and educational factors on the socialization outcomes is mixed and discussed below by categories:

\section{Motivation and expectation}

Students with higher intrinsic motives show declined selfassessment on research skill level, research aspiration, as well as social integration with the academia. Extrinsic incentive is not statistically significantly correlated with changes in self-assessment, research aspiration, and integration outcomes, but students with lower extrinsic incentives tend to remain the same level of certainty about their research concentration. Student career expectation is in general not correlated with socialization outcomes, but those with stronger willingness of taking administrative jobs are less likely to decline in self-assessment or change in certainty about research concentration.

\footnotetext{
9 "Non-key institutions" refers to universities and colleges that are
} not in the "211" Project. 


\section{Environment}

As shown in the table, positive feelings about program environment is significantly associated with a decline in selfassessment on knowledge but an improvement in research aspiration. Positive feelings on globalization environment is significantly associated with unchanged self-assessment on knowledge level, and a tendency of improved social integration with the academia. Other socialization outcomes are not correlated with environment factors.

\section{Student-advisor interaction}

According to the regression outputs, Academic Advice has no significant association with most socialization outcomes. The only exception is for self-assessment on skill level: better academic advice is statistically significantly associated with a higher tendency of declining in self-assessment. Scholarly Guidance appears to be more influential. It is positively correlated with lower likelihood of declined selfassessment on skill level and social integration, and higher likelihood of improvement in research aspiration.

\section{Learning and research experience}

As the Table shows, more engagement in active and collaborative learning is significantly associated with lower likelihood of decline in self-assessment on both knowledge and skill level, but it has no significant correlation with other outcomes. Research engagement is significantly associated with improved self-assessment on knowledge, a lower likelihood of getting unclear of research concentration, but a higher likelihood of declined social integration.

Overall, the multinomial logit regression analysis shows that educational factors, including environment, student-advisor interaction, and learning and research engagement, have a stronger influence on first-year doctoral students' adjustment in self-assessment than on other socialization outcomes. Positive globalization environment, active and collaborative learning, engagement in research, and scholarly guidance from advisor could prevent decline in self-assessment. For the other outcomes, supportive environment could help improve students' research aspiration and level of social integration. Scholarly guidance from advisor could also improve research aspiration, and prevent decline in social integration. Research engagement could help avoid uncertainty on ones' research concentration, but may also make students less socially integrated with the academia. Finally, none of the educational factors (nor the student motivation and expectation) appears to influence student academic integration. As shown in Table 5, about $26.5 \%$ of students become less academically integrated with their research area; however, we are not able to tell from the regression analysis on why this happens and how to address this issue.

\section{Discussion and conclusion}

Using a longitudinal survey data on doctoral students in Tsinghua University, this study explores the gains and changes in attitudes of prospective scholars after their first year in doctoral program. The findings suggest that most students entered the doctoral program in Tsinghua University with proactive attitudes and motivations. In their first year, most students are satisfied with the program environment and research climate, and actively engage in research activities. About $60 \%$ of the students report large gains in academic dispositions after a year, especially knowledge on academic norms and ethics; about half report large gains in knowledge in one's major field and academic skills; but only about 35\% report large improvement in innovation ability; and less than $25 \%$ report large gains in other fields. As for the attitudes on oneself, research work, and integration, most students remain high research aspiration in the first year; nearly half show improved self-assessment and improved social integration with the academia after 1 year; but about $20-27 \%$ of students decline in research aspiration and academic integration after 1 year.

These findings reveal some features of doctoral education in Tsinghua University. First, the finding that first-year doctoral students report higher knowledge gains in their major fields than in other fields demonstrates that doctoral training is a process of specialization into a specific field. Yet, there are about one-third students report working in interdisciplinary research teams. In this new era of rapid knowledge and technology evolvement, foundation of interdisciplinary knowledge becomes increasingly important for innovation. Tsinghua University encourages interdisciplinary collaborations across academic departments, which is also a common trend in the West as noted in Boden et al. (2011). But as Boden and his colleagues pointed out, students working in interdisciplinary programs face more obstacles in their socialization process (Boden et al. 2011). Although we do not look into this issue in this paper, we suggest that more attentions should be given to students working in interdisciplinary research teams.

Second, the student-faculty interaction in Tsinghua doctoral programs tends to be limited to only between student and the academic advisor in the first year. In Tsinghua, students are assigned to academic advisors at the very beginning of the program through a two-way choice process. The findings show that students meet their advisors very frequently, but few of them interact with other faculty members. As suggested in Jazvac-Martek et.al (2011), interacting and collaborating with other academics helps students build 
up network and enhances scholarly commitment. The University needs to encourage doctoral students to engage more with faculty other than their advisor.

Third, the first year in doctoral program is a period of adjustments and changes in self-assessment. While many students become more positive about themselves and their research, about $20 \%$ of students experience a painful process with declined self-assessment, blurred research concentration, and depressed research aspiration. As shown by existing Chinese literature on doctoral students' career choice, the aspiration towards academic work and especially towards research is a key element leading students into academic professions (Bao et al. 2017; Jiang 2011; Lu 2011; Zhao and Hong 2014). The decline in research aspiration shown in our data raises a concern about the future development of our doctoral students.

More surprisingly, students with higher intrinsic motivation at the beginning of the program are more likely to be found frustrated in the first year. This is to some extent contradicted to Lu's (2011) and Jiang's (2011) finding that students with higher aspiration and intrinsic motivation before they entered doctoral program were more likely to choose an academic profession when they graduated. However, as students in our sample are at an early stage in doctoral program, the finding may only suggest that those who start doctoral study with higher aspiration experience a more struggling first year.

This is to some extent understandable. Being admitted to Tsinghua University, one of the top research universities in China, is considered as a big achievement and recognition of one's capability by many students, especially by those with strong interests in doing advanced research. Therefore, the commencement of doctoral program is the point when students are very (but maybe blindly) optimistic about themselves and their research work ahead. Then after a year of studying, doing research, and interacting with professors, peer students, and other people in the program, the newcomers may gradually reveal limitations in their own abilities. They may also find interest in other areas as they get exposed to more research projects, and lose a specific goal to concentrate on. On one hand, such changes may lower students' confidence of being a scholar and commitment to a specific area, but on the other hand, these changes are necessary for a novice scholar to form a realistic evaluation of oneself, and to figure out his/her real research interests. As suggested by the conceptual framework and relevant theories, it is through such iterative self-adjustment and reconstruction do novice students get adapted and integrated to the professional community. We need to wait for data from the last round of survey to reveal the real correlation between motivation at the beginning and career choice upon graduation.

Although the painful self-awareness and adjustment is inevitable and necessary for doctoral students, institutions and advisors can help to smoothen the transition from student to scholar. The regression analysis in this study suggests that, active engagement in learning and research activities is associated with higher gains and lower likelihood of depressed self-assessment. Supportive program environment and environment encouraging global collaboration also contribute to first-year gains and improved research aspiration and social integration. These findings are consistent with existing literature in China and in other countries that informed the conceptual framework of this paper.

Findings on the impact of advisors are in general consistent with previous studies that mentoring plays an important role in helping doctoral students succeed (see for example Anderson and Anderson 2012; Barnes and Austin 2009; Curtin et al. 2013; Eby et al. 2008; Gardner 2008; Hall and Burns 2009). Our study extends the discussion by further separating the advisor's role into academic and scholarly guidance. The findings suggest that what is important in the first year is the scholarly guidance which improves research aspiration and social integration, though it has no correlation with knowledge and skill gains. Academic guidance on the other hand is found to have little influence on first-year outcomes. This may be explained by the procedure of doctoral training in Tsinghua University. Students tend to focus more on course taking in the first year and have not yet been well prepared to discuss advanced academic issues with their advisors even in labs. Yet similar to what Gardner (2008) revealed, the relationship between student and faculty starts to matter at an early stage of doctoral study.

Overall, this study reveals the patterns of doctoral student adaptation in their first year in Tsinghua University. It can be implied from the findings that, adaptation to the scholars' role is not an easy and natural process. This is not unique to Tsinghua University nor to Chinese Universities (see for example Austin 2002; Bao et al. 2017; Curtin et al. 2013; McAlpine et al. 2012; Zhao and Hong 2014). To facilitate the adaptation, doctoral programs need to provide a supportive and open environment, advisors need to give more scholarly guidance, and students need to engage more actively in learning and research activities. This study also reveals a puzzling finding that, although over a quarter of students reported declined satisfaction about their research area, none of the educational factors is found to correlate with such a decline. Further studies are needed to explore possible explanations.

There are some limitations in this study. First, the sample has limited generalizability as it is from a single university in China and over-represented by engineering students. Tsinghua University as one of the best research universities in China has distinguished faculty, outstanding students, and abundant resources. The lessons learned from this special 
case may not be applicable to other universities. In addition, as previous studies revealed, the culture and student socialization experience vary across disciplines (See for example, Boden et al. 2011; Gardner 2008, 2009). The findings from a sample of mostly engineering students need to be interpreted with caution. Further studies need to be done in more universities and diverse academic areas to examine the robustness of the relationships revealed in this study.

Secondly, our study mainly focuses on the socialization to the research role of a scholar. Scholars also take other responsibilities in academic professions such as teaching and service. Doctoral programs should also provide opportunities for students to prepare for these roles. Such issues require further investigations in the future.
Acknowledgements This study is part of the research project titled "Influential factors on doctoral student innovation in Tsinghua University" which is funded by the 2015 Tsinghua University Research Grant for Graduate Education Reform (Special Project Grant). The authors are grateful to Dr. Lin Zhao for all her support and to participants in the 17th International Conference of Education Research for their constructive suggestions.

\section{Appendix}

See Table 8.

Table 8 Measure of variables

\begin{tabular}{|c|c|c|c|c|}
\hline Factors & Indicators & Items (all on 1-6 scales) & No. of items & Cronbach's alpha \\
\hline \multicolumn{5}{|l|}{ Explanatory variables } \\
\hline \multirow[t]{2}{*}{ Motivation (M) } & Intrinsic motivation & $\begin{array}{l}\text { Self-improvement, interests in major } \\
\text { area, interests in exploring the } \\
\text { unknowns }\end{array}$ & 3 & 0.724 \\
\hline & Extrinsic motivation & $\begin{array}{l}\text { Career requirement, "inertia" to get } \\
\text { the next level of education, others' } \\
\text { influence, did not get good jobs }\end{array}$ & 4 & 0.613 \\
\hline \multirow[t]{3}{*}{ Career plan } & Career plan-academic & $\begin{array}{l}\text { Work in the academia (post-docs, } \\
\text { research, and teaching positions) }\end{array}$ & 4 & 0.729 \\
\hline & Career plan-administrative & $\begin{array}{l}\text { Work in the government or taking } \\
\text { administrative positions in other } \\
\text { institutions }\end{array}$ & 3 & 0.712 \\
\hline & Career plan-industry & $\begin{array}{l}\text { Work in the industry or starting own } \\
\text { business }\end{array}$ & 2 & 0.444 \\
\hline \multirow[t]{3}{*}{ Environment } & Program environment & $\begin{array}{l}\text { Basic facilities (5), program plan (5), } \\
\text { academic climate (4), interdiscipli- } \\
\text { nary collaboration (4) }\end{array}$ & 18 & 0.925 \\
\hline & Innovative climate in research team & $\begin{array}{l}\text { Research team encourages discus- } \\
\text { sions and innovation and tolerates } \\
\text { failures }\end{array}$ & 11 & 0.956 \\
\hline & Globalization environment & $\begin{array}{l}\text { Course content and research topics } \\
\text { are in the most advanced areas; } \\
\text { have opportunities to interact/work } \\
\text { with international scholars; have } \\
\text { opportunities to study abroad }\end{array}$ & 5 & 0.842 \\
\hline \multirow[t]{2}{*}{ Student-advisor interaction } & Academic advice & $\begin{array}{l}\text { Availability (5) and capability (8) } \\
\text { of the advisor; prompt feedback } \\
\text { and encouragement (4) from the } \\
\text { advisor }\end{array}$ & 17 & 0.979 \\
\hline & Scholarship guidance & $\begin{array}{l}\text { Equal relationship between students } \\
\text { and advisor (4); Advisor introduce } \\
\text { students into the academia (4) }\end{array}$ & 8 & 0.946 \\
\hline
\end{tabular}


Table 8 (continued)

\begin{tabular}{|c|c|c|c|c|}
\hline Factors & Indicators & Items (all on 1-6 scales) & No. of items & Cronbach's alpha \\
\hline \multirow[t]{2}{*}{ Learning and research experience } & Active and collaborative learning & $\begin{array}{l}\text { Discussion academic topics with } \\
\text { faculty and peer students, active } \\
\text { involvement in academic work } \\
\text { (in-depth exploration on topics, } \\
\text { writing, presentation, attending } \\
\text { lecture) }\end{array}$ & 10 & 0.865 \\
\hline & Research engagement & $\begin{array}{l}\text { Contribute ideas and innovative } \\
\text { designs to the research team, active } \\
\text { engagement in discussion and } \\
\text { research }\end{array}$ & 9 & 0.945 \\
\hline \multicolumn{5}{|l|}{ Outcomes } \\
\hline \multirow[t]{3}{*}{ Self-reported gains } & Knowledge & $\begin{array}{l}\text { Self-reported knowledge gains in } \\
\text { basic theories and advanced topics } \\
\text { in one's major area, and gains in } \\
\text { other areas }\end{array}$ & 3 & 0.818 \\
\hline & Skills & $\begin{array}{l}\text { Self-reported gains in research skills, } \\
\text { academic writing, communica- } \\
\text { tion and collaboration, innovative } \\
\text { ability }\end{array}$ & 5 & 0.929 \\
\hline & Dispositions & $\begin{array}{l}\text { Self-reported improvement in } \\
\text { research aspiration, ethics, and } \\
\text { norms }\end{array}$ & 3 & 0.853 \\
\hline \multirow[t]{2}{*}{ Self-assessment } & Self-assessment on knowledge & $\begin{array}{l}\text { Self-assessment on the level of } \\
\text { knowledge on advanced topics }\end{array}$ & 1 & l \\
\hline & Self-assessment on method & $\begin{array}{l}\text { Self-assessment on the level of mas- } \\
\text { tery of research method }\end{array}$ & 1 & l \\
\hline \multirow[t]{2}{*}{ Commitment and attitude } & Clarity of research concentration & $\begin{array}{l}\text { Self-reported clarity of research } \\
\text { concentration }\end{array}$ & 1 & l \\
\hline & Research aspiration & Attitudes and beliefs about research & 3 & $\begin{array}{l}0.769 \text { (baseline) } \\
0.874 \text { (first year) }\end{array}$ \\
\hline \multirow[t]{2}{*}{ Integration } & Academic integration & Satisfaction on current research area & 1 & l \\
\hline & Social integration & Familiarity with the academia & 1 & l \\
\hline
\end{tabular}

For further information on the definition and measurement of variables, please contact the authors for an unpublished report on the questionnaire design

\section{References}

Anderson, S., \& Anderson, B. (2012). Preparation and socialization of the education professoriate: Narratives of doctoral studentinstructors. International Journal of Teaching and Learning in Higher Education, 24(2), 239-251. Retrieved from http://www. isetl.org/ijtlhe/.

Austin, A. E. (2002). Preparing the next generation of faculty: Graduate school as socialization to the academic career. The Journal of Higher Education, 73(1), 94-122. https://doi.org/10.1353/ jhe.2002.0001.

Bao, W., Du, Q., \& Ma, J. (2017). To be or not to be an Academic: PhD students' career intentions to academia and its influential factors. Journal of Higher Education (in Chinese), 38(4), 61-70.

Barnes, B. J., \& Austin, A. E. (2009). The role of doctoral advisors: A look at advising from the advisor's perspective. Innovative Higher Education, 33(5), 297-315. https://doi.org/10.1007/s1075 5-008-9084-x.

Boden, D., Borrego, M., \& Newswander, L. K. (2011). Student socialization in interdisciplinary doctoral education. Higher
Education, 62(6), 741-755. https://doi.org/10.1007/S1073 4-011-9415-1.

Curtin, N., Stewart, A. J., \& Ostrove, J. M. (2013). Fostering academic self-concept: Advisor support and sense of belonging among international and domestic graduate students. American Educational Research Journal, 50(1), 108-137.

Eby, L. T., Allen, T. D., Evans, S. C., Ng, T., \& Dubois, D. L. (2008). Does mentoring matter? A multidisciplinary meta-analysis comparing mentored and non-mentored individuals. Journal of Vocational Behavior, 72(2), 254.

Gardner, S. K. (2008). "What's too much and what's too little?": The process of becoming an independent researcher in doctoral education. Journal of Higher Education, 79(3), 326-350. https://doi. org/10.1353/jhe.0.0007.

Gardner, S. K. (2009). Conceptualizing success in doctoral education: Perspectives of faculty in seven disciplines. Review of Higher Education, 32(3), 383-406.

Gardner, S. K., \& Mendoza, P. (Eds.). (2010). On becoming a scholar: Socialization and development in doctoral education. Sterling, VA: Stylus Publishing, LLC. 
Hall, L. D., \& Burns, L. (2009). Identity development and mentoring in doctoral education. Harvard Educational Review, 79(1), 49-70. https://doi.org/10.17763/haer.79.1.wr25486891279345.

Jazvac-Martek, M., Chen, S., \& McAlpine, L. (2011). Tracking the doctoral student experience over time: Cultivating agency in diverse spaces. In Doctoral education: Researchbased strategies for doctoral students, supervisors and administrators (pp. 17-36). Dordrecht: Springer. https://doi. org/10.1007/978-94-007-0507-4_2.

Jiang, C. (2011). A study on the determinants of academic career expectation for Chinese doctoral candidates: a dynamic perspective. Peking University Education Review (in Chinese), 9(3), $45-55$.

Kim, J. K. (2009). Socialization and agency of Asian American doctoral students. Philadelphia, PA: University of Pennsylvania.

Lave, J., \& Wenger, E. (1991). Situated learning: Legitimate peripheral participation. Man (Vol. 29). Cambridge: Cambridge University Press. https://doi.org/10.1017/CBO9780511815355.

Lindholm, J. A. (2004). Pathways to the professoriate: The role of self, others, and environment in shaping academic career aspirations. Journal of Academic Librarianship, 75(6), 603-635.

Lu, F. (2011). The factors affecting doctoral students' choice of academic positions. Journal of Yangzhou University (Higher Education Study Edition) (In Chinese), 15(6), 50-55.

McAlpine, L., Jazvac-Martek, M., \& Hopwood, N. (2010). Doctoral student experience in education: Activities and difficulties influencing identity development. International Journal for Researcher Development, 1(1), 97-109.

McAlpine, L., Paulson, J., Gonsalves, A., \& JazvacMartek, M. (2012). "Untold" doctoral stories: Can we move beyond cultural narratives of neglect? Higher Education Research \& Development, 31(4), 511-523. https://doi.org/10.1080/07294360.2011.559199.

Qiu, Y. (2017). World-class doctoral education: The height of talent cultivation in world-class universities. Guangming Daily (in Chinese), p. 16.

Rhoades, G., \& Sporn, B. (2002). Quality assurance in Europe and the U.S.: Professional and political economic framing of higher education policy. Higher Education, 43(3), 355-390.

Rhoads, R. A., Zheng, M., \& Sun, X. (2017). The methodological socialization of social science doctoral students in China and the USA. Higher Education, 73(2), 335-351. https://doi.org/10.1007/ s10734-016-0023-y.

Sweitzer, V. (Baker) (2009). Towards a theory of doctoral student professional identity development: A developmental networks approach. The Journal of Higher Education, 80(1), 1-33. https:// doi.org/10.1353/jhe.0.0034.

Weidman, J. C. (2006). Socialization of students in higher education: Organizational perspectives. In C. F. Conrad \& R. C. Serlin (Eds.), The SAGE handbook for research in education (pp. 252-262). Thousand Oaks, CA: Sage. https://doi.org/10.4135/9781412976 039.n14.

Weidman, J. C., \& Stein, E. L. (2003). Socialization of doctoral students to adacemic norms. Research in Higher Education, 44(6), 641-656. https://doi.org/10.1023/A:1026123508335.

Zhao, Y., \& Hong, Y. (2014). Analysis of the factors influencing the academic occupational orientation of the doctoral recipients. Journal of Beijing University of Technology (Social Sciences Edition) (In Chinese), 14(5), 71-77. 